CARDIOVASCULAR MEDICINE

\title{
Is Mobitz type I atrioventricular block benign in adults?
}

\author{
D B Shaw, J I Gowers, C A Kekwick, K H J New, A W T Whistance
}

Heart 2004;90:169-174. doi: 10.1136/hrt.2003.017806

\begin{abstract}
See end of article for authors' affiliations

.....................

Correspondence to: Dr D B Shaw, Cardiac Department, Room Q242, Royal Devon and Exeter Hospital, Barrack Road, Wonford, Exeter EX2 5DW, UK; davbar66@ btopenworld.com
\end{abstract}

Accepted 29 May 2003

\begin{abstract}
Objective: To assess the need for pacing in adults with chronic Mobitz type I second degree atrioventricular block (Mobitz I).

Design: Prospective study.

Setting: District general hospital.

Patients: 147 subjects aged $\geqslant 20$ years (age cohorts $20-44,45-64,65-79$, and $\geqslant 80$ ) with chronic Mobitz I without second degree Mobitz II or third degree (higher degree) block on entry, seen from 1968 to 1993 and followed up to 30 June 1997. Sixty four had organic heart disease. The presence of symptomatic bradycardia was defined as highly likely in 47 patients (class 1); probable in 14 (class 2); and absent in 86 (class 3).

Interventions: Pacemakers were implanted in 90 patients for the following indications: symptoms in 74 and prophylaxis in 16.

Main outcome measures: The main outcome measure was death, with conduction deterioration to higher degree block or symptomatic bradycardia the alternative measure.

Results: Five year survival to death was reduced in unpaced patients relative to that expected for the normal population (overall mean (SD) 53.5 (6.7)\% v 68.6\%, p $<0.001$; class 3, 54.4 (7.3)\% v 70.1\%, $\mathrm{p}<0.001$ ). Paced patients fared better than unpaced (overall (mean (SD) five year survival $76.3(4.5) \% \mathrm{v}$ $53.5(6.7) \%, p=0.0014$; class 3, 87.2 (5.4)\% v 54.4 (7.3)\%, $p=0.020$; and organic heart disease, $68.2(7.6) \%$ v 44.0 (9.9)\%, $p \leqslant 0.0014)$. There were no deaths in the $<45$ cohort. Survival to first outcome (main or alternative) was further reduced to 31.7 (5.0)\% in 102 patients unpaced initially and $34.2(5.7) \%$ in class 3 . Only the $20-44$ cohort and patients with sinus arrhythmia had $>50 \%$ survival. Conclusion: Mobitz I block is not usually benign in patients $\geqslant 45$ years of age. Pacemaker implantation should be considered, even in the absence of symptomatic bradycardia or organic heart disease.
\end{abstract}

$\mathrm{T}$ raditionally Wenckebach second degree atrioventricular (AV) block (Mobitz I) has been considered benign. A recently reported series of 200 patients fitted with pacemakers from a British district general hospital ${ }^{1}$ did not include patients with Mobitz I. This is in accordance with the American College of Cardiology (ACC)/American Heart Association (AHA) task force guidelines of 1984 and 1991, which considered that pacemaker implantation was unnecessary in patients with Mobitz I unless they had "symptomatic bradycardia" or proven infrahisian block. ${ }^{23}$ While this view is generally accepted for young people and athletes, ${ }^{4-6}$ the British Pacing and Electrophysiology Group (BPEG) working party in $1991^{7}$ suggested that in adults pacing should be considered where block was occurring during much of the day or night irrespective of the presence or absence of symptoms. Following these conflicting recommendations, pacing practice in Europe varied widely; for the year 1992 the ratio of implants for Mobitz I versus Mobitz type II second degree AV block (Mobitz II) varied from $1: 2$ to $1: 7$ ( $1: 2$ in Czechoslovakia, 1:3 in France and Holland, 1:4 in the UK, 1:5 in Austria, and 1:7 in Poland; BPEG and European data courtesy of A F Rickards, personal communication, 1995).

The latest ACC/AHA guidelines of $1998^{8}$ repeated their previous opinion concerning appropriate management of Mobitz I, but qualified it by acknowledging that controversy existed. In general, guidelines have been welcomed in cardiology but concerns have been expressed for the dilemma posed by conflicting recommendations, the problem that guidelines may acquire legal character, and the need for validation. ${ }^{910}$ The BPEG working party and others ${ }^{71-13}$ have referred to our study of $1985,{ }^{14}$ which implied that in older patients the prognosis of chronic Mobitz I was similar to that of Mobitz II and was improved by pacing. However, the study included relatively few patients with Mobitz I and used the single outcome of death. In view of the continuing controversy, we now present survival figures from a larger number of patients with Mobitz I and include the alternative outcomes of deterioration of conduction and development of symptomatic bradycardia, both accepted indications for pacing. In addition the potential risk factors of age, presenting symptoms, associated heart disease and vagal tone, and the possible benefit of pacemaker implantation are assessed.

\section{METHODS}

The study group consisted of patients with Mobitz I notified to the Devon heart block and bradycardia survey ${ }^{15}$ during the period September 1968 to August 1993. The survey recruited directly from general practitioners and physicians of three Devon districts (population approximately 600 000). Excluded were professional athletes and patients with evidence of prior or coincidental Mobitz II or third degree block (higher degree block), transient block following acute myocardial infarction or carditis persisting for less than three weeks, and drug induced block. The criteria were fulfilled by 147 patients. In the absence of complications, patients were reviewed at approximately yearly intervals but by 1997 three had been lost to the study. The footnote to table $1^{16}$ gives clinical details and criteria for hypertension. Criteria for organic heart disease were one or more of ischaemic heart

Abbreviations: ACC, American College of Cardiology; AHA, American Heart Association; AV, atrioventricular; BPEG, British Pacing and Electrophysiology Group; $\mathrm{Cl}$, confidence interval; $\mathrm{RR}$, relative risk 
Table 1 Clinical details

\begin{tabular}{|c|c|c|c|c|c|c|c|c|}
\hline & \multicolumn{6}{|c|}{ On entry } & \multicolumn{2}{|c|}{ On follow up } \\
\hline & \multirow[b]{2}{*}{ Total } & \multirow{2}{*}{$\begin{array}{l}\text { Mean age } \\
\text { (years) }\end{array}$} & \multicolumn{4}{|c|}{ Age cohorts (years) } & \multirow[b]{2}{*}{ Total } & \multirow{2}{*}{$\begin{array}{l}20-44 \\
\text { cohort }\end{array}$} \\
\hline & & & $20-44$ & $45-64$ & $65-79$ & $\geqslant 80$ & & \\
\hline \multicolumn{9}{|l|}{ Reasons for referral } \\
\hline Disturbed consciousness (class 1) & 42 & 70.5 & 5 & 4 & 20 & 13 & & \\
\hline Possible cardiac symptoms (class 2 ) & 36 & 68.8 & 2 & 7 & 22 & 5 & & \\
\hline Coincidental (class 3) & 58 & 69.9 & 6 & 0 & 24 & 18 & & \\
\hline Uncoded/unknown & 11 & 62 & 2 & 4 & 4 & 1 & & \\
\hline Total & 147 & 69.3 & 15 & 25 & 70 & 37 & & \\
\hline Sex ratio (men:women) & 1.9:1 & & $10: 5$ & $16: 9$ & $47: 23$ & $25: 12$ & & \\
\hline \multicolumn{9}{|l|}{ Data discovered during survey } \\
\hline Syncope/presyncope ${ }^{*}$ & 45 & 71.8 & 3 & 6 & 24 & 12 & 16 & 3 \\
\hline Bradycardia induced dizziness/confusion & 15 & 68.6 & 1 & 3 & 10 & 1 & 4 & 0 \\
\hline Bradycardia induced dyspnoea & 11 & 75.1 & 0 & 0 & 10 & 1 & 9 & 0 \\
\hline Angina of effort† & 18 & 72.3 & 0 & 3 & 11 & 4 & 17 & 1 \\
\hline Hypertension $\ddagger$ & 23 & 76 & 0 & 2 & 16 & 5 & & \\
\hline Myocardial infarction & 21 & 72.7 & 0 & 4 & 11 & 6 & 6 & 0 \\
\hline Valvar or congenital heart disease & 16 & 63.5 & 2 & 7 & 6 & 1 & 6 & 0 \\
\hline Cardiac failure & 7 & 78.8 & 1 & 0 & 3 & 3 & 20 & 1 \\
\hline Rheumatic fever§ & 19 & 68.1 & 2 & 4 & 10 & 3 & 0 & 0 \\
\hline Organic heart disease & 64 & 71.2 & 2 & 13 & 37 & 12 & & \\
\hline Mobitz I on standard or ambulatory ECG & 112 & 71.6 & 8 & 15 & 57 & 32 & & \\
\hline Mobitz I initially on ambulatory ECG only & 35 & 62 & 7 & 10 & 13 & 5 & & \\
\hline Bundle branch block & 40 & 73.6 & 2 & 5 & 20 & 12 & 7 & 0 \\
\hline 2:1 Block & 34 & 72.9 & 2 & 4 & 20 & 7 & 22 & 2 \\
\hline Advanced block & 3 & 66.3 & 0 & 1 & 2 & 0 & 9 & 1 \\
\hline $\mathrm{PP}$ interval varies $\leqslant 60 \mathrm{~ms}$ with Mobitz $\left.\right|^{* *}$ & 81 & 73.7 & 2 & 13 & 43 & 23 & & \\
\hline $60 \mathrm{~ms}<\mathrm{PP}$ interval $<120 \mathrm{~ms}$ with Mobitz $\mathrm{I}^{* *}$ & 12 & 67.8 & 2 & 1 & 5 & 4 & & \\
\hline Sinus arrhythmia with Mobitz l** & 25 & 53.8 & 9 & 8 & 4 & 4 & & \\
\hline Mobitz I during bradycardia** & 30 & 56.4 & 10 & 7 & 9 & 4 & & \\
\hline His high block/prolonged $\mathrm{AH}$ intervalł‡ & 14 & 57.1 & 4 & 3 & 7 & 0 & & \\
\hline
\end{tabular}

disease (past, clinical, or ECG evidence of myocardial ischaemia or infarction or cardiomyopathy), valvar or congenital heart disease, hypertension, or cardiac failure excluding that solely caused by cardiac arrhythmia.

\section{Electrocardiography}

Mobitz I was diagnosed based on standard criteria ${ }^{17}$ and reviewed according to Barold and Barold's refinements. ${ }^{18}$ Blocked $\mathrm{P}$ waves followed by escape beats were a problem for classification in respect of suspected Mobitz II but in the case of Mobitz I serial ambulant recordings showed uninterrupted Wenckebach series in all but one instance. ${ }^{19}{ }^{20}$ First degree AV block defined as a PR interval $>200$ ms measured after a blocked $\mathrm{P}$ wave or during runs of $1: 1$ conduction was present in 86 patients. No inference on the site of block was attributed to 2:1 block or to sequences of two or more blocked $\mathrm{P}$ waves (advanced AV block). ${ }^{21}$ Sinoatrial dysfunction was present in five patients.

Vagal drive was assessed by measurement to the nearest $20 \mathrm{~ms}$ of up to five PP intervals before and after a blocked beat at times of constant overall heart rate (PP within $40 \mathrm{~ms}$ at start and finish of sequence). Suitable records (423) showing block in 118 patients were analysed and classified into three referral groups (table 1). Where different degrees of variability were found, the most pronounced was coded. Thirty two patients performed effort tolerance tests. His bundle electrograms and sinus node recovery times were measured in 19 patients and split His potentials were sought. ${ }^{22}$

Pacemakers were implanted in response to incapacitating symptoms or the development of higher degree block, indications closely resembling the ACC/AHA guidelines of 1984. ${ }^{2}$ After 1982 older patients were offered pacemaker implantation prophylactically if there were no contraindications.

\section{Data analysis}

In addition to death, two alternative outcomes during follow up were used that are risk factors for death and reduce quality of life:

- deterioration of conduction to higher degree block (either episodic or persistent)

- onset of various other forms of symptomatic bradycardia, as defined in the ACC/AHA guidelines,[2] where previously absent.

Survival was calculated for the group as a whole and separately for paced and unpaced patients divided into four cohorts by age (table 1). Patients who were initially left unpaced $(\mathrm{n}=102)$ were analysed in respect of the alternative outcomes. Survival was calculated in months from the first prospective visit or from presurvey data if available ( $\mathrm{n}=30$ cases $)$ to death or to the last follow up appointment.

Analysis was by the life table method. ${ }^{23}$ Survival was compared between groups by the log rank test. ${ }^{24}$ Age imbalance between groups was adjusted and the groups compared with Cox's proportional hazards model..$^{24}$ Survival curves were compared with those from an age and sex matched general population obtained from mortality data from the Office for National Statistics ${ }^{26}$ and were tested by the Kolmogorov-Smirnov one sample test. ${ }^{27}$ Confidence intervals (CI) are 95\% throughout. Other than in the age and sex matched comparisons no allowance was made for sex differences since AV node function appears to be similar in both. ${ }^{28}$ In respect of alternative outcomes, higher block rarely develops in the general population including those with isolated first degree block. ${ }^{29}{ }^{30}$ In the absence of precise data for comparison with the findings in this study, the curve for time to higher block or death was compared with the age and sex matched normal population. The incidence of 
complete block in the normal population was estimated from the pacemaker implants in Scotland, England, and Wales for 1996, the year that had the highest rates in five year age groups (BPEG database, A D Cunningham, personal communication, 2001). Even a 50\% underestimate by this method would make a less than $1 \%$ change in survival for the normal population, an error considered insignificant for the purposes of this study. The incidence of symptomatic bradycardia in the paced patients was compared with that in the unpaced patients.

\section{Referral groups and symptom classes}

The patients' state on entry was classified by referral group and symptomatic class. Reasons for referral were amalgamated into three groups with a fourth for uncodeable reasons.

- Syncopal reason for referral was defined as a disturbance of consciousness (syncope or presyncope)

- Cardiac reason was palpitation, breathlessness, chest pain, or suspected cardiac failure

- Coincidental reason was discovery of Mobitz I on the preoperative ECG, during the health check, or during an intercurrent infection or other disease.

If both of the first two were present, referral was classified as syncopal.

Symptom classes were defined as follows:

1. Highly probable: typical history of symptomatic bradycardia

2. Probable: a degree of uncertainty concerning the symptoms or the part played by bradycardia

3. No symptoms of bradycardia.

Class 1 and 3 accorded with those used by the ACC/AHA (1984) guidelines, ${ }^{2}$ and class 2 acknowledged doubt as to the relevance of bradycardia rather than the philosophy concerning the conduction defect.

\section{RESULTS}

\section{Outcome of death}

Most patients in the syncopal and cardiac referral groups had symptomatic bradycardia on entry (52 of $78(67 \%)$ in the combined groups) and satisfied the criteria for classes 1 or 2 . Those in the coincidental group were predominantly in class $3(54$ of $58(93 \%))$. Paradoxically the symptomatic groups had a significantly better rate of survival (fig 1). The main difference, other than survival, was the numbers given pacemakers (63 of $78(81 \%)$ and 21 of $58(36 \%)$, respectively). Overall the prognosis of unpaced patients was poor compared with the normal population, including those in class 3 (fig 2).

\section{Pacemaker implantation}

Ninety patients received pacemakers, half of them immediately after initial assessment. Dual chamber systems (DDD) were used in 23 and ventricular (VVI) in 67. The indications for pacing on entry were symptomatic bradycardia in 36 and prophylaxis for uncomplicated Mobitz I in nine. Of those who later received a pacemaker the indications were symptomatic bradycardia or higher degree block in 38 and prophylaxis in seven. Incorporating presurvey data favoured survival of unpaced patients to a greater extent than paced (improving the five year survival by $3.6 \% \vee 1.0 \%$ ), but paced patients still fared significantly better than unpaced patients (table 2 ).

None of the patients in the first age cohort (20-44 years), with or without a pacemaker, died within 14 years, but in the second (45-64 years) and third cohorts (65-79 years) the difference in survival between patients with and those without a pacemaker was highly significant (table 2). In

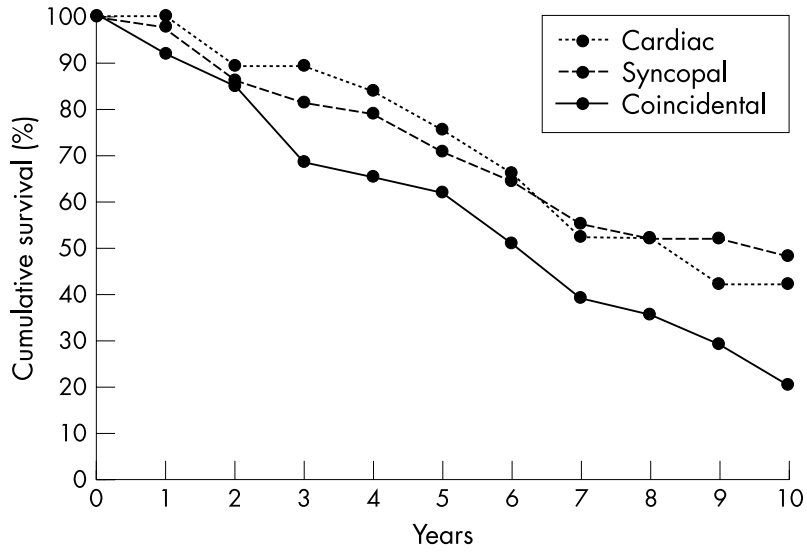

Figure 1 Survival for patients grouped according to reason for initial ECG and referral to the study. The difference between the curves of the coincidental referral group and the other two groups combined was significant ( $p<0.03$, log rank test).

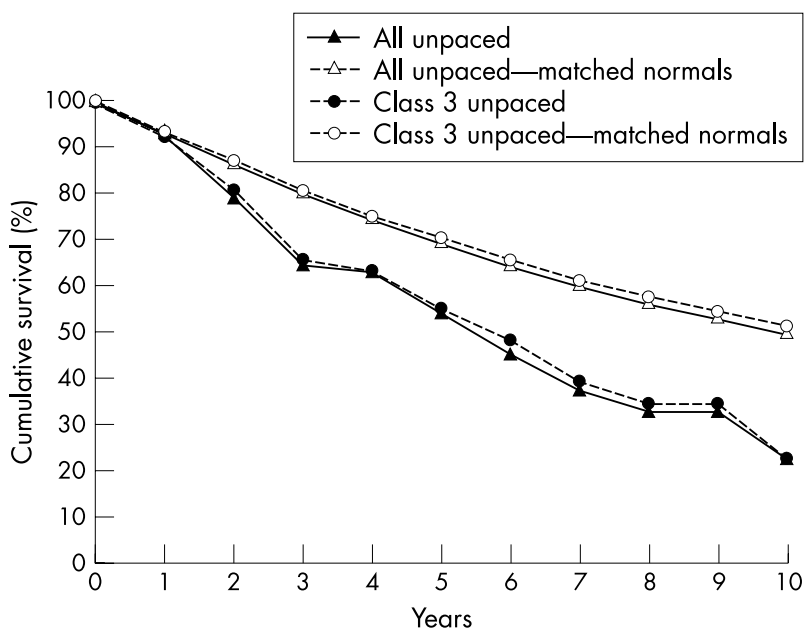

Figure 2 Life table survival curves for patients with Mobitz I atrioventricular block who did not receive a pacemaker and for matched normal populations. Differences between curves both from all cases and from class 3 and the corresponding expected normal values are highly significant ( $p<0.001$, Kolmogorov-Smirnov one sample test).

the fourth cohort $(\geqslant 80$ years) patients with a pacemaker had a better five year survival than those without, but the difference was not significant.

As expected, paced patients fared better than unpaced patients in classes 1 and 2, but few were unpaced and they were much older. In class 3 the numbers of paced and unpaced were more evenly balanced with similar mean ages and proportions with organic heart disease (18 of 39 (46\%) and 22 of $47(47 \%))$. Here the benefit in survival was highly significant.

In other groups, paced patients fared better than unpaced patients; table 2 gives significant differences. In addition, survival appeared to be prolonged in paced compared with unpaced patients in sinus arrhythmia (relative risk (RR) 0.29 , $95 \%$ CI 0.07 to $1.22, p=0.09$ ) and to a lesser extent in the subgroups with no organic heart disease and variable PP interval $(60 \mathrm{~ms}<\mathrm{PP}<120 \mathrm{~ms})$.

In unpaced patients, those with bundle branch block fared worse than those without (RR 2.00, 95\% CI 1.01 to 3.96, $\mathrm{p}=0.047$ ). The risk was greater in the group where Mobitz I was discovered on ambulant ECG than in patients in whom it was found on standard ECG, after correcting for age and pacing (RR $1.36,95 \%$ CI 0.77 to 2.40 ). 
Table 2 Survival of patients with versus those without a pacemaker

\begin{tabular}{|c|c|c|c|c|c|c|c|}
\hline Group & & Total & $\begin{array}{l}\text { Mean age } \\
\text { (years) }\end{array}$ & $\begin{array}{l}5 \text { year survival } \\
\text { (\% (SD) }\end{array}$ & Relative risk & $95 \% \mathrm{Cl}$ & $p$ Value \\
\hline \multirow[t]{2}{*}{ All patients } & Paced & 90 & 69.6 & $76.3(4.5)$ & & & $0.0014^{*}$ \\
\hline & Unpaced & 57 & 68.8 & $53.5(6.7)$ & & & \\
\hline \multirow[t]{2}{*}{ Age cohort 20-44 } & Paced & 5 & 34.0 & $100(0.0)$ & & & 1.00 \\
\hline & Unpaced & 10 & 32.6 & $100(0.0)$ & & & \\
\hline \multirow[t]{2}{*}{ Age cohort 45-64 } & Paced & 18 & 57.1 & $94.4(5.4)$ & & & $0.001^{*}$ \\
\hline & Unpaced & 7 & 58.1 & $57.1(18.7)$ & & & \\
\hline \multirow[t]{2}{*}{ Age cohort 65-79 } & Paced & 52 & 72.9 & $76.6(5.9)$ & & & $0.003^{*}$ \\
\hline & Unpaced & 18 & 72.2 & $50.0(11.8)$ & & & \\
\hline \multirow[t]{2}{*}{ Age cohort $\geqslant 80$} & Paced & 15 & 85.0 & $45.9(13.0)$ & & & $0.76^{*}$ \\
\hline & Unpaced & 22 & 85.9 & $33.4(10.3)$ & & & \\
\hline \multirow[t]{2}{*}{ Class 3 (no bradycardia) } & Paced & 39 & 67.5 & $87.2(5.4)$ & & & $0.020^{*}$ \\
\hline & Unpaced & 47 & 67.8 & $54.4(7.3)$ & & & \\
\hline \multicolumn{8}{|l|}{ Other groups } \\
\hline \multirow[t]{2}{*}{ Organic heart disease } & Paced & 38 & 69.8 & $68.2(7.6)$ & 0.36 & 0.20 to 0.68 & $0.0014 \dagger \ddagger$ \\
\hline & Unpaced & 26 & 73.2 & $44.0(9.9)$ & & & \\
\hline \multirow[t]{2}{*}{ Mobitz I on ambulatory ECG only } & Paced & 27 & 65.0 & $80.3(7.9)$ & 0.23 & 0.05 to 1.01 & $0.051 \dagger$ \\
\hline & Unpaced & 8 & 51.8 & $62.5(17.1)$ & & & \\
\hline \multirow[t]{2}{*}{ Bundle branch block } & Paced & 26 & 71.7 & $72.7(8.8)$ & 0.34 & 0.14 to 0.80 & $0.024 \dagger$ \\
\hline & Unpaced & 14 & 70.0 & $23.1(11.7)$ & & & \\
\hline \multirow[t]{2}{*}{ No bundle branch block } & Paced & 64 & 68.8 & $77.8(5.2)$ & 0.54 & 0.03 to 0.89 & $0.023 \dagger$ \\
\hline & Unpaced & 43 & 66.1 & $62.7(7.4)$ & & & \\
\hline \multirow[t]{2}{*}{ PP intervals varies $<60 \mathrm{~ms}$} & Paced & 46 & 72.4 & $80.1(5.9)$ & 0.44 & 0.25 to 0.77 & $0.004 \dagger$ \\
\hline & Unpaced & 35 & 75.3 & $47.2(8.6)$ & & & \\
\hline
\end{tabular}

His bundle electrograms showed an AH interval $>200 \mathrm{~ms}$ or intermittent high block in 14 patients (HV 70-80 ms in one), in whom survival appeared to be worse than in the other 133 patients (RR 1.54, 95\% CI 0.27 to 3.34). No instances of split His were recorded.

\section{Alternative outcome}

Alternative outcomes were recorded in 59 patients after entry to the study (fig 3). Forty six developed higher degree AV block (three with Mobitz II and 45 with complete block, two having both). Most instances of higher block occurred before pacing but six followed implantation. Symptomatic bradycardia developed after entry in 27 of $102(26 \%)$ patients but did not persist in any after pacing.

In 102 patients who did not have a pacemaker on entry and were followed up for 5902 months the incidence of higher block was 85 per thousand per year, whereas the age matched pacemaker implantation rate in the UK for complete heart block during 1996 was 92 per million per year (BPEG database).

Other than the first cohort (20-44 years) and those entering with sinus arrhythmia, survival to an alternative or first outcome (including death) at five years was $<50 \%$, including patients in the oldest cohort and those without heart disease.

Patients with bundle branch block fared marginally worse than those without, but both groups did worse than the matched normal population (fig 4). Alternative outcomes were recorded for 11 patients with His electrograms, six with high block, four with low block, and one with a normal His electrogram.

\section{DISCUSSION}

The use of presurvey data for 30 patients modifies the prospective nature of the study but was considered appropriate since the effect was to lengthen the survival of unpaced patients. This would be antithetical to Mobitz I being a specific risk factor and that pacing was beneficial. In addition it seemed perverse to date onset of Mobitz I from the first survey assessment when the condition was known to have been present for some time already. If pacemaker implantation were to be considered in patients without symptomatic bradycardia, it would be important to study outcome from the initial diagnosis.

Patients, mainly unpaced, discovered to have Mobitz I coincidentally fared worse than those referred because of suspected syncope or other cardiac symptoms, despite being similar in respect of mean age and incidence of organic heart disease. The absence of symptomatic bradycardia on entry was no guarantee of subsequent freedom from deteriorating conduction, symptomatic bradycardia, or premature death. Over two thirds of such patients suffered from one of these outcomes within five years. This is at variance with traditionally held beliefs and the conclusions of the ACC/ AHA task force reports. ${ }^{238}$

The task force referred to evidence from Strasberg and colleagues, ${ }^{31}$ who stated that "without complicating organic heart disease, chronic second degree AV nodal block is usually benign" and commented that pacing was not helpful in those with heart disease unless there were other indications. These views were based on a study of 56 patients with second degree AV nodal block (all with ECG evidence of Mobitz I) divided into two groups. Group 1 consisted of 19 patients without organic heart disease; 14 were younger than 45 , and 7 were athletes. Other than the inclusion of athletes, this group was similar to our youngest cohort. In both studies the prognosis was relatively good. Their group 2 (37 patients) shared features with our 64 patients with organic heart disease. Unpaced, these patients fared badly in both studies. However, in the former, heart disease was advanced, 24 being in cardiac failure (a high risk group irrespective of management, ${ }^{32}{ }^{33}$ ) and only 10 were paced. In contrast the Devon study had few patients in heart failure and over half were paced, with a highly significant improvement in survival. We suggest that the data from both studies are compatible with the proposition that Mobitz I in patients aged $\geqslant 45$ years is, per se, an indication for pacing to improve both survival and quality of life (the latter being a major factor in the very old). Younger patients manage well unpaced, although even here the condition is not always benign. ${ }^{34}$

The service implication of pacing most patients with Mobitz I may be best assessed as the potential increase in relation to current implants for complete heart block (the 
Figure 3 Survival to first outcome including death and to alternative outcome alone in age cohorts and to first outcome in other groups.

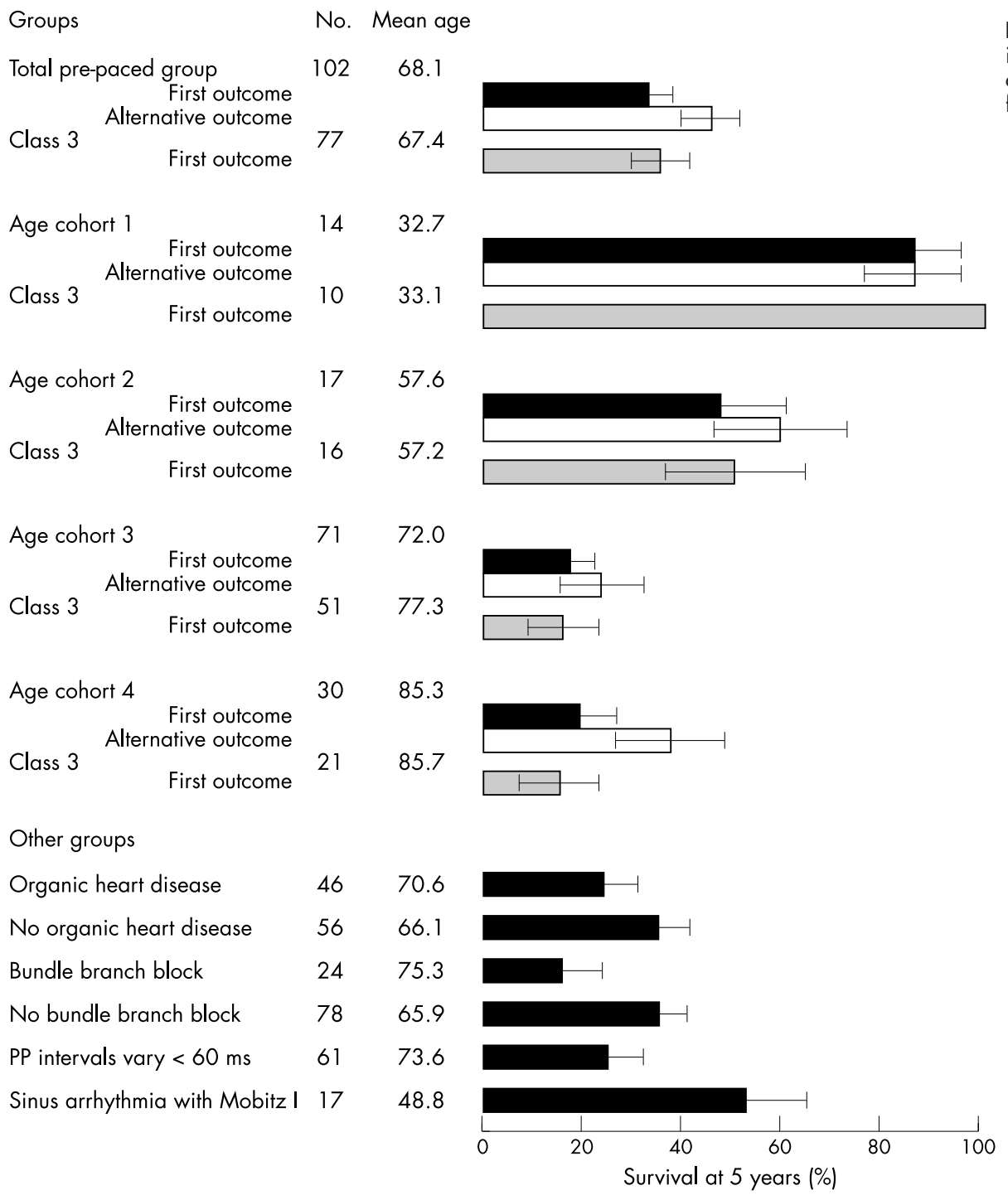

$\begin{array}{lr}\text { Class } 3 & \begin{array}{r}\text { Alternative outcom } \\ \text { First outcom }\end{array}\end{array}$

Age cohort 1

Class $3 \quad$ Alternative outcom
Age cohort 2 First outcome

\section{Class 3}
First outcome
Age cohort 3 First outcome

\section{Class 3} ative outcome
Age cohort 4 Five outcome

\section{her groups}

\section{Organic heart disease}

No organic heart disease

Bundle branch block

PP intervals vary $<60 \mathrm{~ms}$

73.6

48.8

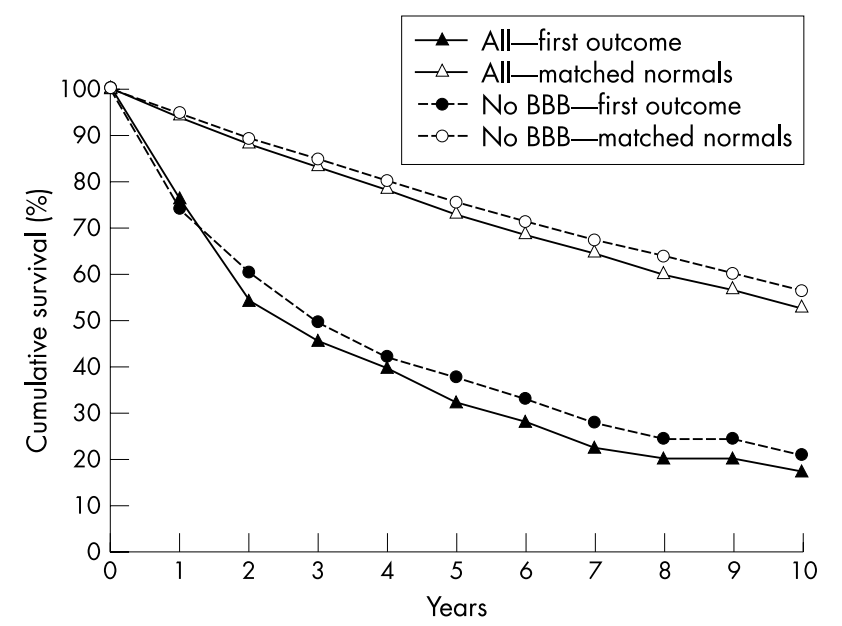

Figure 4 Survival to the first outcome (death, deterioration in conduction, or symptomatic bradycardia) in patients with Mobitz I and to death in a matched normal population. Curves for those unpaced on entry $(n=102)$ and those without bundle branch block (BBB) $(n=78)$ were highly significantly different from those of the normal population ( $p<0.001$, Kolmogorov-Smirnov one sample test). numbers of which have been relatively constant in the past six years), since costs vary between cardiac units and countries. In our database the incidence of Mobitz I in comparison with that of complete heart block was $14 \%$. However, since the Devon heart block survey was well known to the general practitioners in the area, our pickup rate may have been higher than in other services. Furthermore, half (74 of 147) of the patients were paced for standard indications during the study. Currently DDD systems are likely to be used in the majority of patients with complete block and Mobitz I, possibly with more VVI units in the former (say $40 \%$ and 10\%, respectively). Analysis of the literature from 1996 indicated that despite the greater initial cost of DDD units, in the third year after implantation the cumulative costs of complications were lower than for those for VVI units. ${ }^{35}$ However, the total difference in cost benefit between the two systems remains controversial. ${ }^{86}$ The mean age of unpaced patients with Mobitz I was much the same as that reported for complete block in the UK. However, according to our recommendations, those who received a pacemaker later in the study would instead have had a pacemaker implanted at the time of entry, which would have added two years to follow up costs. If our survey population is representative, our calculations suggest that pacing the two conditions similarly would be unlikely to add more than $8 \%$ 
to the current cardiac department budget for complete heart block.

\section{Conclusions}

Mobitz I was not benign in most of those studied who were aged $\geqslant 45$ years. The majority, including patients in whom Mobitz I was discovered coincidentally or without symptomatic bradycardia, progressed to higher degree block, developed symptoms of bradycardia, or died prematurely if left unpaced. Other than age, organic heart disease and bundle branch block appear to be additional risk factors. No group with completely benign risk was identified, although patients with increased vagal tone did marginally better than the rest. Except for the youngest cohort, survival was significantly better for paced than for unpaced patients in virtually all groups studied.

\section{ACKNOWLEDGEMENTS}

The Devon heart block and bradycardia survey was initially funded by the Department of Health and the British Heart Foundation. The current study was supported by grants from the Northcott Devon Medical Foundation and the Oxenham Trust.

\section{Authors' affiliations}

D B Shaw, J I Gowers, C A Kekwick, K H J New, A W T Whistance, Cardiac Department, Royal Devon and Exeter Hospital, Exeter, UK

\section{REFERENCES}

1 Eltrafi A Currie P, Silas JH. Permanent pacemaker insertion in a district general hospital: indications, patient characteristics and complications. Postgrad Med J 2000;76:337-9.

2 Frye RL, Collins JJ, de Sanctis RW, et al. Guidelines for permanent cardiac pacemaker implantation, May 1984: a report of the Joint American College of Cardiology/American Heart Association Task Force on Assessment of Cardiovascular Procedures (Subcommittee on Ppacemaker Implantation). Circulation 1984;70:331A-9A.

3 Dreifus L, Fisch C, Griffin JC, et al. Guidelines for implantation of cardiac pacemakers and antiarrhythmia devices: a report of the American College of Cardiology/American Heart Association Task Force on Assessment of Diagnostic and Therapeutic Cardiovascular Procedures (Committee on Pacemaker Implantation). J Am Coll Cardiol 1991;18:1-13

4 Brodsky M, Wu D, Denes P, et al. Arrhythmias documented by 24 hour continuous electrocardiographic monitoring in 50 male medical students without apparent heart disease. Am J Cardiol 1977;39:390-5.

5 Zeppilli P, Fenici R, Sassara M, et al. Wenckebach second-degree A-V block in top-ranking athletes: and old problem revisited. Am Heart $J$ 1980;100:281-94.

6 Viitasalo MT, Kala R, Eisalo A. Ambulatory electrocardiographic recording in endurance athletes. Br Heart J 1982;47:213-20.

7 Clarke M, Sutton R, Ward D, et al. Recommendations for pacemaker prescription for symptomatic bradycardia: report of a working party of the British Pacing and Electrophysiology Group. Br Heart J 1991;66:185-91.

8 Ritchie JL, Gibbons RJ, Cheitlin MD, et al. Guidelines for implantation of cardiac pacemakers and antiarrhythmia devices: a report of the American College of Cardiology/American Heart Association Task Force for Practice Guidelines. (Committee on Pacemaker Implantation). J Am Coll Cardio 1998:31:1175-209.
9 Bassand JP, Ryden L. Guidelines: making the headlines or confined to the sidelines? Eur Heart J 1999;20:1149-51.

10 Schwartz PJ, Breithardt G, Howard AJ, et al. The legal implications of medical guidelines: a task force of the European Society of Cardiology. Eur Heart J 1999:20:1152-7.

11 Zipes DP. Second degree atrioventricular block. Circulation 1979;60:465-72

12 Rosenqvist $M$, Norlander R. Survival in patients with permanent pacemakers. Cardiol Clin 1992;10:691-703.

13 Connelly DT, Steinhaus DM. Mobitz type I atrioventricular block: an indication for permanent pacing? Pacing Clin Electrophysiol 1996;19:261-4

14 Shaw DB, Kekwick CA, Veale D, et al. Survival in second degree atrioventricular block. Br Heart J 1985;53:587-93.

15 Shaw DB, Eraut D. Prevalence and morbidity of heart block in Devon. BMJ 1970;i:144-7.

16 Anon. Guidelines for the diagnosis of rheumatic fever: Jones criteria, 1992 update. Special Writing Group of the Committee on Rheumatic Fever, Endocarditis and Kawasaki Disease of the Council of Cardiovascular Disease in the Young of the American Heart Association. JAMA 1992;268:2069-73.

17 Zipes DP. Specific arrhythmias: diagnosis and treatment. In: Braunwald E, ed. Heart disease: a textbook of cardiovascular medicine, 5th edn. Philadelphia: W B Saunders, 1997:640-704.

18 Barold SS, Barold HS. Pitfalls in the characterization of second-degree AV block. Heartweb 1997:970400.www.heartbeat.org/heartweb/0497/ p0002.htm.

19 Massie B, Scheinman MM, Peters R, et al. Clinical and electrophysiologic findings in patients with paroxysmal slowing of the sinus rate and apparent Mobitz type II atrioventricular block. Circulation 1978;58:305-14.

20 Barold S. The Chicago School of Electrocardiography and second-degree atrioventricular block: an historical perspective. Pacing Clin Electrophysiol $2001 ; 24: 138-46$.

21 Castellanos A, Moleiro F. The Chicago School of Arrhythmology: an analysis of a revisionist view. Pacing Clin Electrophysiol 2001;24:135-7.

22 Guimond C, Puech P. Intra-His bundle blocks (102 cases). Eur J Cardiol 1976;4:481-93.

23 Cutler SJ, Ederer F. Maximum utilization of the life-table method in analyzing survival. J Chronic Dis 1958;8:699-712.

24 Altman DG. Practical statistics for medical research. London: Chapman and Hall, 1991:371-5,387-93.

25 Tibshirani R. A plain man's guide to the proportional hazards model. Clin Invest Med 1982;5:63-8.

26 Anon. Office for National Statistics. English life tables no 15. London: The Stationery Office, 1997.

27 Sokal RR, Rohlf P. Biometry, 2nd edn. San Francisco: WH Freeman, 1981:716-21

28 Taneja T, Mahnert BW, Passman R, et al. Effects of sex and age on electrocardiographic and cardiac electrophysiological properties in adults. Pacing Clin Electrophysiol 2001;24:16-21.

29 Camm AJ, Evans KE, Ward DE, et al. The rhythm of the heart in active elderly subjects. Am Heart J 1980;99:598-603.

30 Mymin D, Frances AL, Mathewson MD, et al. The natural history of primary first-degree atrioventricular heart block. N Engl J Med 1986;315:1183-7.

31 Strasberg B, Amat-Y-Leon F, Ramesh C, et al. Natural history of chronic second degree atrioventricular nodal block. Circulation 1981;63:1043-9.

32 Muller CH, Cernin J, Glogaret D, et al. Survival rate and causes of death in patients with pacemakers: dependence on symptoms leading to pacemaker implantation. Eur Heart J 1988;9:1003-9.

33 Mayosi BM, Little F, Scott Millar RN, et al. Long-term survival after permanent pacemaker implantation in young adults: 30 year experience. Pacing Clin Electrophysiol 1999;22:407-12.

34 Young D, Eisenberg R, Fish B, et al. Wenkebach atrioventricular block (Mobitz type I) in children and adolescents. Am J Cardiol 1977;40:393-9.

35 Sutton R, Bourgeoist I. An economic sensitivity analysis of the literature. Eur Heart J 1996; 17:574-82.

36 Vassolo M, Lamas GA. Dual-chamber vs ventricular pacing in the elderly: quality of life and clinical outcomes. Eur Heart J 1999;20:1607-8.

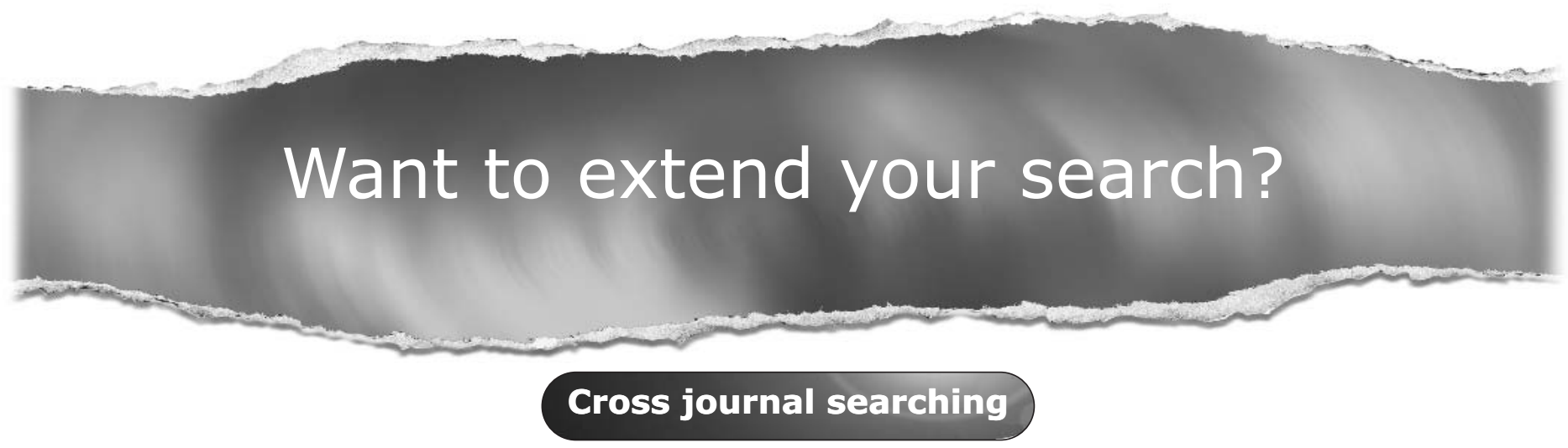

Can't find what you're looking for in Heart? Extend your search across $340+$ journals. Search restriction options include specific subject areas (eg. clinical medicine, basic research), select specific journals or search all available titles. 